\title{
Will Public-Private Partnerships Solve Nigeria’s Infrastructure Problems?
}

\begin{abstract}
George Nwangwu
Correspondence: George Nwangwu, Research Fellow, African Procurement Law Unit, Department of Mercantile Law, Stellenbosch University, South Africa and Honorary Senior Research Associate, The Bartlett School of Construction \& Project Management, University College London, London, United Kingdom.
\end{abstract}

Received: April 24, 2019

doi:10.11114/smc.v9i1.4118

\author{
Accepted: May 17, 2021 \\ Online Published: May 24, 2021 \\ URL: https://doi.org/10.11114/smc.v9i1.4118
}

\begin{abstract}
Nigeria, like most countries around the world, has turned to Public-Private Partnerships (PPPs) to finance its infrastructure deficit. However, it appears that the government of Nigeria looks towards PPPs as the major solution to the country's infrastructure crisis. In a sense PPPs are being sold to the public as if they were free, that the private sector would come in with its funds, provide the desired services and that the problem with the country's infrastructure would automatically cease. This paper argues that this supposition is a myth and that the role of PPPs in the provision of public infrastructure is more nuanced than is being bandied around. PPPs are not the panacea to all of the country's infrastructure problems and also are far from being completely free. It is however the case that if appropriately deployed, in most cases PPPs provide some advantages over conventional public sector procurements. This paper explores the different advantages and disadvantages of PPPs and suggests ways in which PPPs may be effectively used to improve the country's infrastructure with reduced fiscal exposure to government.
\end{abstract}

Keywords: public-private partnerships, infrastructure, Nigeria, private finance initiative

\section{Introduction}

The state of Nigeria's infrastructure is abysmal. According to the National Integrated Infrastructure Master Plan, it is estimated that $70 \%$ of the federal road network are not in good condition, $78 \%$ of state roads are in poor condition and $87 \%$ of local roads are also in poor condition (National Planning Commission, 2014). Nigeria's power sector is also poor with power generation mostly below 5000MW (National Planning Commission, 2014). The National Integrated Infrastructure Master Plan states that Nigeria's current infrastructure stock ranges between $20 \%$ to $25 \%$ of GDP; this is way below the international benchmark of about 70\% (National Planning Commission, 2014). The major reason adduced for this state of affairs is the paucity of public funds. For instance, the Infrastructure Concession Regulatory Commission (ICRC) estimates that the country requires about USD 100 billion in the next six years to enable the country bridge its infrastructure gap (Infrastructure Concession Regulatory Commission, 2018). However, the Nigerian government has not been able to come up with the right amount of investment required to provide acceptable levels of infrastructure. This has led to the clamour for the use of private sector investments especially through PPPs to help bridge the gap.

The idea that PPPs may be deployed for financing infrastructure is not new. There is a growing trend across the world where PPP and other similar structures have been successfully deployed to augment government budgets to provide infrastructure across several countries. However, PPPs have never been a silver bullet for resolving all the issues relating to the provision of infrastructure. This is because amongst other things, PPPs can be very expensive when deployed under certain conditions and are sometimes not suitable for use in the provision of certain social services or even in some infrastructure sectors. It however appears that these apparent limitations to the use of PPPs are lost on the policy makers within Nigeria. The general narrative around PPPs in Nigeria appears to be that PPPs can resolve most, if not all of the infrastructure challenges confronting the country and that private sector actors are in a position to develop infrastructure at little or no cost to government. This is evidenced from the different policy speeches by government officials (Abuja Inquirer, 2018) and spinets of this can be found in official economic policy documents like the Economic Recovery and Growth Plan (ERGP) (Ministry of Budget and National Planning, 2017), National Infrastructure Master Plan (National Planning Commission, 2014) and the National PPP Policy (Infrastructure Concession Regulatory Commission, 2009). document, to mention a few. However, the most obvious evidence is from the manner in which PPP projects are being procured and delivered across the country. An example of this is the 
propensity of the public sector to seek to transfer all the project risks to the private sector party regardless of whether it is ideal, extract maximum concession fees from the private sector parties, sometimes at the detriment of the project and neglecting to meet their contractual obligations to private sector investors. These are all actions that show clearly that the mindset of the government is that the private sector investors should bear the entire burden for developing PPP projects.

It appears that there are two major policy thrusts for the use of PPPs for infrastructure. The first is the simple financial argument. This policy thread is the narrative that due to limited finances, governments require private sector investments to make up the financing gap required to fund infrastructural deficits. The problem with this argument is that it is not only limited in scope but can also be misleading. As has been argued above, PPPs are not free as governments pays for the services delivered through PPPs one way or the other. These are either through availability payments or through user fees made by the user public. Where citizens pay tolls or user fees to private sector service providers, governments effectively forgo the right to collect these fees as taxes, tying it instead to the payment for particular services provided by the private sector partners. Also, where PPPs are solely used as a means to finance infrastructure, it blunts out other potential benefits that can be garnered from PPPs. Therefore, governments that focus their PPP policies solely on the financial benefits to be derived from PPPs lose sight of more important benefits that may be derived from employing PPPs, usually leading to unsuccessful PPP programmes.

The second policy thread is the use of PPPs as a management tool. When PPPs are used in this manner, it is to the effect that PPPs promote an efficient and competitive procurement regime, which ensures that only the best partners are given the opportunity to develop and operate infrastructure. The rigorous analysis and market testing which PPPs undergo ensures reduced whole life cycle costing and promotes value for money. It also ensures that the private sector parties are allocated risks and responsibilities that ensure that they deploy their superior expertise in delivering projects that add value to the end user public and save government money.

The problem is that this very important management policy reason for the use of PPPs is hardly ever emphasized in Nigeria, with attention only paid to the use of PPPs as a tool for raising finance for infrastructure. This paper argues that this approach affects the public perception of the concept and might lead to the Nigerian government not even achieving its desired goal of bridging the infrastructure gap through PPP financing. Both policy approaches are not mutually exclusive but rather complementary. This is because at the core of the efficiency argument is the view that if PPPs are done properly, it leads to less expensive, more efficient and better-operated infrastructure. Therefore, it is only when the two policy threads are effectively combined that the rich benefits of PPPs are enjoyed. It also ensures that the user public buy into the PPP programmes as their expectations are better managed and they are armed with a comprehensive verifiable set of objectives with which they can holistically evaluate projects.

\section{What Are PPPs?}

Prior to the explosion in the use of PPPs, public infrastructure like highways, bridges, railways, power plants and prisons where mostly financed, constructed, operated and maintained by government through its different public agencies. Typically, government would through a public procurement process award the contract for the construction of the infrastructure to a private sector entity and pay such private sector contractor through budgetary allocations. The operation and periodic maintenance of the publicly procured assets were then subsequently financed and done directly by government through the budget. What PPP as a method of procurement has done is that it has bundled a combination or all of the financing, construction, operation and maintenance of public infrastructure into a single long term contract between a public agency and the private sector party. During the lifespan of the contract, the private sector party receives a stream of revenues as compensation for its investment in the infrastructure. This compensation would typically cover the initial capital cost of the project, the operational expenses, the maintenance cost and an agreed return on the investment. These revenues may come directly as user fees from the user public or in the form of periodically made availability payments from the government or even a combination of both. Typically, the assets revert back to the government at the end of the contract.

Like most terms of its ilk, there is no consensus on the definition of a PPP, there are indeed variations in the way in which the concept has been defined. The multitude of definitions of the concept in existence is influenced primarily by the fact that different professions, countries, institutions and even political parties employ the concept to achieve their own specific needs (Nwangwu, 2013). Nevertheless, there appears a general level of agreement on what constitutes a PPP. For the purposes of this paper, a PPP may be defined as a long term relationship between public sector agencies and private sector entities under which the responsibility for any or all of the combination of designing, financing, construction, management and operation of public infrastructure and utilities that were traditionally undertaken by the public sector are contractually shared and jointly undertaken by both the public and private sector, usually in proportion to the kind of risks each party can best carry (Nwangwu, 2013). 
The Malaysian PPP Guidelines identifies some elements of PPPs:

i. The relationship between the public and private sector parties is based on a partnership, which means that risk is shared between both partners optimally as it is allocated to the party who is best able to manage it.

ii. The public sector procures specified outputs and outcomes of a service for the contract period whilst the private sector determines the required inputs to achieve the specified output and are given the freedom to introduce innovation into their design and development to reduce cost; There is thus an integration of design, construction, finance and maintenance and operation

iii. Payment for services is based on predetermined standards and performances

iv. PPP promotes a 'maintenance culture' where the private sector will be responsible for the long term maintenance of the assets throughout the operational period agreed upon by the parties;

v. In some instances, there is an option for the transfer of the infrastructure asset back to the public sector at the end of the contract period.

vi. $\quad$ PPP involves a Whole Life Cycle Costing ("WLCC") whereby PPP projects are usually awarded based on lowest total cost over the contract period compared to lowest construction cost under traditional procurement (Putrajaya PPP Unit, 2009)

\section{Why Do Governments Use PPPs?}

The overwhelming motivation for governments around the world for the use of PPPs, appears to be the inadequacy of public funds to meet the increased demand for infrastructure (Grimsey and Lewis, 2004; Albert, Chan and Kajewski, 2009). Therefore it is not surprising that most governments, including the Nigerian government, view PPPs as a costless means of financing infrastructure projects. The argument is usually that by getting the private sector to finance PPPs projects, the government is able to deploy scarce resources for other social purposes. This is erroneous as there are no costless PPP projects. PPPs at best merely suspend the payment for the infrastructure to a future date. Under the availability payment method of funding PPPs, the government still makes periodic payments for services rendered; while under the user fee payment schemes, payments made by the public may be viewed as indirect taxes that are collected from citizens as governments effectively delegate their rights to collect taxes from citizens to the private sector operators.

It is also the case that even in situations where the government concedes that the PPP projects would involve the expenditure of public funds, the projects are still conceived as being extra budgetary in order to avoid any possible budget ceiling or restriction. Governments are mostly able to achieve this by structuring PPPs in a manner that presents the projects as being financed outside of the government balance sheet. This is possible due to the fact that most public sector accounting rules do not account for expenditure made by the private sector in delivering PPP projects as they are not usually considered part of the public debt. This is also regardless of whether the project is likely to generate considerable contingent liabilities.

Another reason why PPPs are often considered to be more expensive than conventionally procured projects is that being long term contracts, they are susceptible to re-negotiations. Some of the re-negotiations may be permissible since they arise due to unforeseen changes in the economic, political or social fundamentals of the contract. This is not uncommon in PPP contracts, as the length of the term of PPP contracts distorts the bargain of the parties. However, some of the reasons for contractual re-negotiations may arise from the opportunistic behaviors of the private sector parties. For instance, some bidders for PPP projects deliberately bid opportunistically to win projects by whatever means and then come back to renegotiate projects after signing the contracts. This invariably makes the project more expensive than earlier envisaged and ensures that the benefits arising from the competitive nature of PPP procurements are lost.

In the absence of the other benefits that accrue to PPP projects, they might end up being more expensive than publicly procured projects as it is usually cheaper for governments to borrow than the private sector. The reason for this is that the market considers it less risky to lend to sovereigns. It may well be the case that the reason why governments seem to borrow cheaper than the private sector is that lenders tend to look at the global risk of the country when they lend to government as opposed to evaluating the individual projects on their own merits. Therefore, it might well be that the high borrowing costs which PPPs face are because of better project evaluation by lenders.

The requirements for sovereign guarantees, viability gap funding (VGF) and other incentive schemes offered by the government to the private sector might make PPPs more expensive than traditionally procured projects. When viewed critically, these risk mitigating instruments typically make projects cheaper for investors by de-risking the projects. However, this does not make the risks disappear; it merely transfers the risks back to the public sector party through explicit or contingent liabilities. In some instances, private sector parties have relied on overly optimistic revenue 
assumptions, with dire consequences for the private sector. The further challenge for the government with this is that even where such projects progress with guarantees, government's contingent liabilities increase and eventually crystalize with devastating consequences. Badly prepared projects are more rampant where guarantees are issued indiscriminately to private sector parties. This unwittingly transfers project risks back to the government and reduces the incentive for the private sector to carry out rigorous project analysis. It is essential that a project guarantee dependent culture is not allowed to take root where instead of proper project analysis, private sector depends on sovereign guarantees.

\section{Benefits Derived from PPPs}

Although the argument that PPPs are costless or cheaper than traditional procurement does not hold water, there are benefits inherent in the use of PPPs to procure infrastructure projects. These benefits in themselves are sufficient incentives for the use of PPPs. There are countries that realize this and have effectively utilized PPPs as an organizational or management tool. For instance, the Netherlands has adopted PPP-type structures primarily to promote an efficient procurement regime and reform its public sector (Harris, 2012). PPPs have also been utilised variously as a governance or management tool and as a development strategy

The following are some of the benefits that may accrue from focusing on PPPs as a management tool:

\subsection{Risk}

One of the major advantages of PPPs over other procurement models is the transfer of risk from the public sector to the private sector (Grimsey and Lewis, 2004). One of the essential roles of PPPs therefore is to achieve optimal risk allocation. This ensures that parties are able to contribute their skills and expertise to the projects focusing on the areas where they can comparatively manage the risks better and therefore cheaper. Under traditional procurement, the risk assumed by the public sector when it owns and operates an infrastructure asset is often unvalued. What PPP ensures through the involvement of the private sector is that risk is adequately and properly identified, priced and then transferred to the party that is best able to manage it. Under traditional public procurement, decisions on options to follow in procuring a particular project is based on a cost benefit analysis that does not consider alternative ways of procuring the project but assumes a particular commercial approach, which is often procurement by the public sector. Once the procurement approach is decided, the public sector sets in motion a competition between bidders where price and non-price factors are assessed to ensure that VFM is achieved. However, in PPPs, the test for VFM is two-pronged: first there is competition between bidders like under traditional procurement. Secondly, the choice of a particular arrangement is also tested to ensure that it is capable of delivering VFM to the government (Grimsey and Lewis, 2004).

It is assumed that risk transfer will create value for the project and lead to savings on whole life cycle costs. The essence of the "partnership" in PPPs is the fact that parties are able to share the risks and rewards so that the party best able to assume a particular risk shoulders it. It is therefore not wise to transfer all the risks to the private sector as that would greatly impair the profitability and consequently the feasibility of the project. This will lead to either the abandonment of the project by the private sector, or escalate the cost of the project thereby reducing its economic viability, as the private sector will cost every risk allotted to it and charge a premium for them.

It is apposite to note however that not everyone agrees that risk transfer to the private sector always leads to positive outcomes. There are contrary views to the effect that risk management practices could be highly variable, intuitive, subjective and unsophisticated (Akintoye, 2001; Loosemore, 2007). One of the foremost criticism of the management of risks in PPP projects is that PPP contracts usually involve lengthy and complex contract tendering procedures with a large number of stakeholders participating in the process. It is therefore argued that the complex nature of PPP procurements actually increases public sector risk rather than reduces it, increases service costs for the public and represents a barrier to the entry of small companies, which is patently uncompetitive (Loosemore, 2007; Moore and Muller, 1989). Another argument is that in certain situations PPPs are not economically viable for the private sector without exorbitant risk-related service charges, which are saddled on the public (Moore and Muller, 1989). Also, due to the long-term nature of PPP contracts and the changing nature of risks over the term of the PPP contract, there are doubts that parties will be able to fully conceive all probable risks that will materialize during the life span of the project. Therefore, in order to compensate for these unknown risks, the private sector consortium demands high-risk premiums that are eventually transferred to the public in the form of high user fees or availability payments (Moore and Muller, 1989).

However despite these criticisms, there is superior literature and arguments as discussed above to the effect that it is more desirable and rewarding to properly manage risks in PPPs (Grimsey Lewis, 2005). Consequently, this is because there is a correlation between the proper transfer and management of risk and the improvement of value for money in projects. The reason for this is simply because when parties expressly assume risks in projects, they now become more conscious of these risks and are able to reduce either the probability of the risk occurring or the financial consequences 
if it does, or both (Grimsey Lewis, 2005). Accordingly, it is important, that every PPP project strives towards the proper allocation of risk between the public and private sectors as this is one of the most important advantages that may be derived from PPPs.

\subsection{Value for Money}

One of the major reasons for adopting PPPs is the claim that PPPs provide better value for money (VFM) for the public sector than traditional procurement. However, it is not all PPP projects that create VFM. Therefore, in deciding whether to finance a project through PPPs rather than via traditional public sector procurement, the government will usually test whether the PPP alternative presents better VFM for the public sector party. As noted above, proper risk allocation in a project usually contributes to the attainment of VFM. Cheung et al carried out a comparative study of Hong Kong, Australia and the United Kingdom and discovered that proper risk allocation was the greatest VFM enabler in all three jurisdictions (Cheung et al., 2009). They discovered that when risks are properly handled, the project is susceptible to fewer pitfalls and $t$ this leads to the achievement of VFM (Cheung et al., 2009). In a similar vein, Bing Li et $a l$ whilst conducting a research on the factors that enhanced VFM in PPP projects found that the top three factors are efficient risk allocation, output-based specification and the long-term nature of contracts (Li B. et al.,2006; Anderson, 2000).

VFM is not an easy term to define because of its political underpinnings. The way it is defined thus depends on the motives and interests of the party carrying out the definition. It may therefore change over time due to political, economic and social developments (Ismail, 2011; Akintoye, 2003). The term "VFM" may either be used as an absolute or relative term. As an absolute term, it can be taken to mean that the benefits of purchase to the purchaser exceed the costs, while as a relative term it means that one of the options for meeting the purchaser's needs provides greater benefits relative to cost than the other (Infrastructure Concession Regulatory Commission, 2009). According to the UK HM Treasury Value for Money Guide, VFM is "the optimum combination of whole-of-life costs and quality (or fitness for purpose) of the goods or service to meet the users requirements. VFM is not the choice of goods and services based on the lowest cost of the bid" (Treasury, 2006; Takim et al., 2011). In essence the UK HM Treasury's definition underlines that in determining the value of pursuing a project as a PPP, the public sector must account for the cost savings to be made from the project over the lifetime of the project. In addition, it stresses that VFM assessment should ensure that the public agencies focus on the competency of the private sector, not only on securing the lowest bids (Treasury, 2006).

According to Grimsey and Lewis, a number of conditions ought to be met in order to achieve VFM in projects: Firstly, projects should be awarded in a competitive environment. Secondly economic appraisal techniques, including proper appreciation of risk, should be vigorously applied, and risk allocated between the public and private sectors so that the expected value of money is maximized. Finally, the comparisons between publicly and privately financed options should be fair, realistic and comprehensive (Grimsey and Lewis, 2005). VFM itself is a broad term that captures both financial and non-financial elements of evaluations (Takim et al., 2011). To ensure that the analysis of the two alternatives available to the government is comparable, there will be a need for a proper accounting for quality of services, price, timeframe, risk apportionment and certainty (Department of Treasury and Finance, 2011). VFM is often computed in most jurisdictions by using a benchmark called the Public Sector Comparator ("PSC"). The PSC simply describes the options and assesses what it would cost the public sector to provide the outputs it is requiring from the private sector on its own. Thus the private sector bids are assessed against the PSC to determine which of the two options will guarantee better VFM (Grimsey and Lewis, 2002)

In essence, where PPPs are sold to the user public and delivered in a manner that ensures that they deliver VFM, it becomes a very attractive proposition.

\subsection{PPPs Lead to Greater Efficiency}

PPPs if done properly are most likely to lead to greater efficiency and merit in a government's procurement of goods and services. PPPs are able to ensure that public funds are spent wisely on deserving projects and in sectors that create the greatest value. This is made possible because by its nature, PPPs promote full costing at an early stage in project development. A private sector investor would be unlikely to invest in a project that is not viable, unlike public sector procurements which may be pursued for other political considerations. All these ensure that "white elephant" projects or the proverbial "bridge that goes to nowhere" are avoided as only deserving projects are pursued. In addition, it provides a key management tool during the procurement process by focusing attention on the output specification, risk allocation and comprehensive costing, allowing for proper contract management during the operational phase of the project. Also, it provides a consistent benchmark and an evaluation tool for projects through the use of the PSC or similar methodology. Finally, PPPs encourage competition first between two different procurement options and then amongst bidders; these process help in generating confidence in the market that financial rigor and probity principles have applied to the project thereby making financing of the project easier (Grimsey and Lewis, 2004). 


\subsection{Avoiding Cost Overruns}

PPPs ensure that projects are completed on time and that the risks of costs overrun and contract variations are significantly diminished (Anastasopoulos and Haddock, 2014). This is achieved by transferring construction risk, both in terms of cost and duration, to the private sector party. Construction risk is transferred to the private sector by bundling the entire PPP value chain under a Build Operate Transfer (BOT) for instance and making the private sector party responsible for their delivery. Therefore, if the private sector party is unable to complete the build aspect on time or fails to do so within budget, it loses money. It is also the case that once the term of the contract starts to run, the period of the concession begins to shrink. Therefore, due to the fact that the private sector investor is likely to lose out if the project is delayed, there is an added incentive to speed up the project and avoid anything that would increase the project cost unduly.

This is particularly important in Nigeria where most projects suffer sever cost overruns due principally to the inefficiencies in implementing government budgets. There is hardly any major publicly procured project that has been delivered within time and within the stipulated timeframe. Therefore even though construction costs may appear higher under PPPs, the money saved from avoiding cost overruns will most likely cover whatever initial savings (Blanc-Brude, 2006).

\subsection{Guaranteed Operations and Maintenance.}

By bundling the construction, operation and maintenance of the assets, PPPs ensure that assets are properly operated and continuously maintained by the private sector operators. The payment of user fees usually also ensures that the user public demand better services as the public see a direct correlation between the money spent and the quality of services provided. This will solve the problem that is encountered in Nigeria where public infrastructure is usually poorly maintained thereby costing so much more to rehabilitate in the future.

\subsection{Fighting Corruption}

PPPs are essential to the fight against corruption. Public procurements in most developing countries are usually opaque. In Nigeria for instance, despite the enactment of the Procurement Act, 2007, it is an exception rather than the norm to witness a transparent public procurement process. The winners of bids are long decided before the projects even make their way into the budget or are advertised for expression of interests from prospective bidders. Also, under public procurement, where the management of the infrastructure assets are in the hands of public sector officials, the chain of corruption continues as further dubious contracts are awarded to operate and maintain the assets and when the assets are finally in near collapse due to the previous corrupt procurement processes, another dubious contract is awarded for a turnaround maintenance which is another term for retrofitting or replacement of the infrastructure.

PPPs help fight corruption first of all because of the competitive and transparent procurement process that projects undergo before they are delivered. Secondly, PPPs by excluding public sector from the operation of the assets, deny public sector officials the opportunity to influence the award of contracts during the operational phase of the project. This, more than anything, saves the public enormous resources that would have otherwise ended up in private pockets.

\subsection{Political Considerations}

PPPs allow for the management of public infrastructure services in more politically attractive forms than nationalization or privatization (Savas, 2007). Citizens are usually suspicious and wary of their governments divesting public services to private sector. This is why there has been so much resistance against privatizations across the world (Uba, 2008). PPPs provide a good alternative as it does not lead to a complete divestiture of the public asset. Unlike under privatisation, ownership of the assets remains in the hands of the private sector and only operation is transferred to the private sector and even this reverts to the public sector at a future date. For this reason, it is easier for governments to sell PPPs as an economic policy than as outright privatisations.

\section{Conclusion}

Presently, PPPs are sold as the panacea for all of the many infrastructure challenges confronting Nigeria. This paper shows that this is not correct and that whilst PPPs have a number of advantages, they are incapable of solving the myriad of infrastructure challenges confronting the country. The paper advances the argument that one of the principal reasons for the low success rate of PPPs within Nigeria is because of the government focusing principally on PPPs as a financing tool with little attention to the immense potential PPPs have as a management tool. Also it needs to be realized that PPPs are not without flaws. For instance, it has been suggested that PPPs have tended to be more expensive than traditional procurement solutions due to the high cost of borrowing available to the private sector, exorbitant transaction fees, high administrative charges/fees for managing PPP transactions and over reliance on guarantees by private sector, thereby increasing government's contingent liabilities significantly. Also PPPs are very complex arrangements requiring very expensive consultants to deliver (Grimsey and Lewis, 2007). These are the 
problems that must be addressed by any PPP programme.

The paper also shows that PPPs have advantages that far outweigh its disadvantages. It is only when these enormous advantages of PPPs are better appreciated and effectively communicated, that the tone is set for better project risk management and therefore the delivery of more sustainable projects. Consequently, it is advocated that the messaging about what PPPs are and what the government is able to achieve through them should change. The way PPPs are delivered should also reflect the fact that PPPs deliver more than just providing government with additional or alternative financing as they could also be an effective mm management tool.

\section{References}

Abuja, I. (2018). Adeosun Seeks PPP to Address Infrastructural Dearth. http://www.theabujainquirer.com/?page=465\&get=Adeosun_seeks_PPP_to_address_infrastructural_dearth_465

Akintoye, A. (2001). Framework for Risk Assessment and Management of Private Finance Initiative Projects Glasgow, Scotland, UK; Glasgow Caledonia University

Akintoye, A. (2003). Achieving Best Value in Private Finance Initiative Project Procurement. Construction Management and Economics, 21, 461-470.

Albert, C. E., Chan, P. C., \& Kajewski, S. (2009). Reasons for Implementing Public Private Partnership Projects: Perspectives from Hong Kong, Australian and British Practitioners. Journal of Property Investment and Finance, 27(1), 81-95.

Anastasopoulos, P. C., \& Haddock, J. E. (2014). Cost Overrun in Public-Private Partnerships: Towards a Sustainable Highway Maintenance and Rehabilitation. Journal of Construction Engineering and Management, 140.

Andersen, A. (2000). Value for Money Drivers in Private Finance Initiative Arthur Andersen and Enterprise LSE

48

Blanc-Brude et al (2006). Ex-ante Construction Costs in the European Road Sector: A Comparison of Public-Private Partnerships and Traditional Public Procurement. Economic and Financial Report No. 2006/01

Cheung, E. et al. (2009). Enhancing Value for Money in Public Private Partnership Projects: Findings from a Survey Conducted in Hong Kong and Australia Compared to Findings from Previous Research in the UK. 14(1) Journal of Financial Management of Property and Construction pp. 7-20.

Department of Treasury and Finance, South Australia. (2011). Partnership South Australia Guidelines, http://www.treasury.sa.gov.au/public/download.jsp?id=513

Grimsey, \& Lewis. (2007). Public-Private Partnerships and Public Procurement. Agenda, 14(2), 171-188.

Grimsey, D., \& Lewis, M. K. (2002). Evaluating the Risk of Public Private Partnerships for Infrastructure Projects. International Journal of Project Management, 204, 107-118.

Grimsey, D., \& Lewis, M. K. (2004). Public Private Partnerships: The Worldwide Revolution in Infrastructure Provision and Project Finance, Cheltenham, Edward Elgar

Grimsey, D., \& Lewis, M. K. (2005). Are Public Private Partnerships Value for Money: Evaluating Alternative Approaches and Comparing Academic and Practitioner Views. Accounting Forum, 29, 345-378

Harris, S. (2012). Public Private Partnerships: Delivering Better Infrastructure Services (Working Paper) Inter-American Development Bank, Washington DC 3

Infrastructure Concession Regulatory Commission. (2009). National Policy on Public- Private Partnerships (PPPs)

Infrastructure Concession Regulatory Commission. (2018). Filing Nigeria's Infrastructure Gap. http://www.icrc.gov.ng/filling-nigerias-infrastructure-gap/

Ismail, K. et al. (2011). The Evaluation Criteria for Value for Money (VFM) of Public Private Partnership (PPP) Bids" International Conference on Intelligent Building and Management Proc. of CSIT, 5.

Li, B. et al. (2006). VFM and Risk Allocation Models in Construction PPP Projects. Preliminary Result of On-going $\mathrm{PhD}$ Research, School of Built and Natural Environment, Glasgow Caledonia University http://www.reading.ac.uk/AcaDepts/kc/ARCOM/eorkshop/04-Edinburgh/06-Li.pdf

Loosemore, A. N. (2007). Risk Allocation in the Private Provision of public Infrastructure. International Journal of Project Management, 25, 66-76.

Ministry of Budget and National Planning. (2017). Economic Recovery and Growth Plan, 2017-2020. 
Moore, W. B., \& Muller, T. (1989). Impacts of Development and Infrastructure Financing. Journal Urban Plan Development, 115(2), ASCE 95-108

National Planning Commission. (2014). National Integrated Infrastructure Master Plan. http://www.niimp.gov.ng

Nwangwu, G. (2013). A Risk Based Approach to Enhancing Public-Private Partnership Projects in Nigeria. PhD Thesis, University of Hull, U.K.

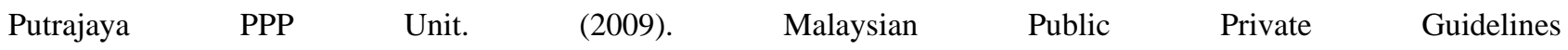
http://www.ukas.gov.my/html/themes/miu/content/ppp_bi_131109.pdf

Savas, E. S. (2007). Privatization and Public-Private Partnerships, New York: Chatham House

Takim, R. R. et al. (2011). A Value for Money Assessment Method for Public Private Partnership. A lesson from Malaysian Approach. International Conference on Economics and Finance Research IPEDR 4

Treasury, H. M. (2006). Value for Money Assessment Guide, HM Treasury London

Uba, K. (2008). Labour Union Resistance to Economic Liberalization in India: What Can National and State Level Patterns of Protests Against Privatizations. Tell Asian Survey, 48(5), 860-884. 